\title{
Switching Angles Optimization of Cascaded Multilevel Inverter with Newton-Raphson Method
}

\author{
Krismadinata $^{1 *}$, Syahril ${ }^{2}$, Irma Husnaini ${ }^{3}$, Asnil ${ }^{4}$ \\ 1,2,3,4 Faculty of Engineering, Universitas Negeri Padang West Sumatera 25131 Indonesia \\ *Corresponding Author: krisma@ft.unp.ac.id
}

\begin{abstract}
This paper recounts an approach to optimize the switching angles of single-phase five-level cascaded $\mathrm{H}$-bridge multilevel inverter. Optimized Harmonic Elimination Stepped Waveform (OHESW) technique was engaged to enhance the output waveform quality. Newton-Raphson method is employed to determine the switching angles for the inverter which eliminates specified higher order harmonics while maintaining the required fundamental voltage. Computation resulting from the optimized switching angle was simulated. Its results indicated the proposed method's effectiveness
\end{abstract}

Key words: multilevel inverter; Newton-Rapson; OHESW

\section{Introduction}

Inverter is one of popular power converters in renewable energy technology, especially for photovoltaic system. Inverter is circuit that convert power from a direct current (DC) source to an alternative current (AC) load. There are many types of inverters. Multilevel inverters that one of them have been attracting attention for their high-voltage operation capability, high efficiency and low electromagnetic interference (EMI). Multilevel inverters produce a desired output voltage from several levels of DC voltages as inputs. By taking sufficient number of DC sources, a nearly sinusoidal voltage waveform can be achieved. [1]

Various topologies for multilevel inverters have been proposed; the most popular being the diode-clamped [2-4], flying capacitor[5], and cascade H-bridge [6] structures. Among the three topologies, the cascaded $\mathrm{H}$ bridge $(\mathrm{CHB})$ inverter topology has the potential to be the most reliable and achieve the best fault tolerance owing to its modularity, a feature that enables the inverter to remain working at lower power levels after cell failure. Modularity also permits the cascaded multilevel inverter to be arranged easily for high power and highvoltage applications. Moreover, the switching stress for each power switching would be less than the regular two level topology, since the switch and diode need only withstand one separate DC voltage.

Multilevel inverter's efficiency considerations such as switching losses and harmonic reduction principally depend on its modulation strategies, which can be categorized according to the switching frequency used. Multilevel inverter control techniques are based on fundamental and high switching frequencies.

Selective harmonic elimination (SHE) technique with optimized harmonic elimination stepped waveform for low switching frequency is very suitable for a multilevel inverter circuit. It can reject some specific harmonic components.

Optimized switching angles are computed by solving transcendental equation from non-linear equation SHE-OHESW technique. Solution methods for non-linear transcendental equations have been reported. Optimization technique based on Genetic Algorithm (GA) is proposed for computation of the switching angles for a five-level inverter [7-9]. Transcendental equations converted into polynomial equations are then solved via the method of resultants from the elimination theory proposed in [10]. Neural network has been investigated by $[11,12]$. Newton-Raphson method can be used to solve the non-linear equations of OHESW technique [13. 16].

\section{CHB Multilevel Inverter}

Figure 1 is a single-phase structure of a $\mathrm{CHB}$ multilevel inverter. It consists of 2 single-phase H-bridge inverters that connected in series to generate five level output phase voltage. The output voltage of cascaded multilevel inverter is equal to the summation of the output voltages of the respective modules that is

$$
V_{o}=V_{m 1}+V_{m 2}
$$

Where $V_{0}=$ output voltage inverter, $V_{m 1}=$ output voltage of module 1 and $V_{m 2}=$ output voltage of module 2 
Each module of this inverter has its own DC source $\left(\mathrm{V}_{\mathrm{dc}}\right)$ and consists of four power devices designated as $S_{\mathrm{t}}$, $S_{2 i}, S_{3 /}$ and $S_{4 i}$. the symbol $i$ is number of module.

The states of operation switching for this inverter to generate five output voltage levels $\left(+2 \mathrm{~V}_{\mathrm{dc}},+\mathrm{V}_{\mathrm{dc}}, 0\right.$, $-\mathrm{V}_{\mathrm{dc}}$, and $-2 \mathrm{~V}_{\mathrm{dc}}$ ) are shown in Table $\mathrm{I}$.
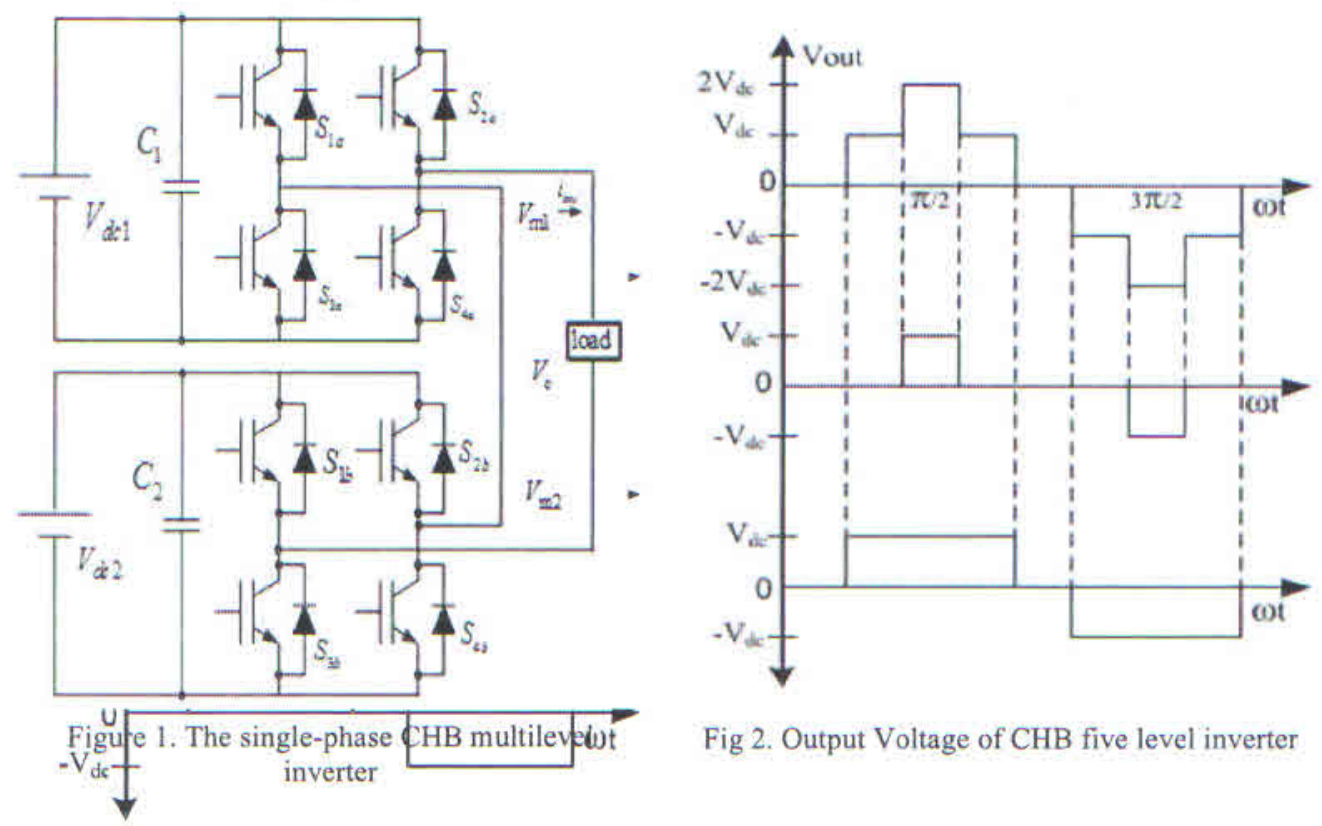

Fig 2. Output Voltage of CHB five level inverter

Table I. Output voltage according to the switches on-off condition,

\begin{tabular}{|c|c|c|c|c|c|c|c|c|c|c|}
\hline \multicolumn{8}{|c|}{ Power devices index } & \multicolumn{3}{|c|}{ Output voltage } \\
\hline$S_{1 \mathrm{a}}$ & $S_{2 a}$ & $S_{3 \mathrm{u}}$ & $S_{4 a}$ & $S_{1 \mathrm{~b}}$ & $S_{2 b}$ & $S_{3 \mathrm{~b}}$ & $S_{4 b}$ & $V_{\mathrm{m} 1}$ & $V_{\mathrm{m} 2}$ & $V_{0}$ \\
\hline 1 & 0 & 0 & 1 & 1 & 0 & 0 & 1 & $+V_{d c}$ & $+V_{d c}$ & $2 V_{d c}$ \\
\hline 0 & 0 & 0 & 1 & 1 & 1 & 0 & 0 & $+V_{d c}$ & 0 & $+V_{d c}$ \\
\hline 1 & 1 & 0 & 0 & 1 & 1 & 0 & 0 & 0 & 0 & 0 \\
\hline 0 & 1 & 1 & 0 & 0 & 0 & 1 & 0 & $-\mathrm{V}_{\mathrm{dc}}$ & 0 & $-\mathrm{V}_{\mathrm{de}}$ \\
\hline 0 & 1 & 1 & 0 & 0 & 0 & 1 & 0 & $-\mathrm{V}_{\mathrm{dc}}$ & $-\mathrm{V}_{\mathrm{dc}}$ & $-2 V_{d c}$ \\
\hline
\end{tabular}

An inverter's performance, with any switching strategy, is generally accepted as relating to its output by solving selective harmonic elimination equations in such a way that the fundamental voltage is voltage's harmonic content. For a multilevel inverter, switching angles at fundamental frequency are obtained as desired and specific lower order harmonics are eliminated.

Figure 3 shows five levels of output-voltage waveforms. Waveform for $V_{a-b}$ is known as an odd-quarter waveform symmetric with 2 positive steps of equal magnitude each, i.e., $V_{\mathrm{dc}}$. The Fourier series for a periodic function can be expressed as:

$$
V_{a b}(w t)=\left(V_{d c}\right) \frac{4}{n p} \sum_{n=1,3,5}^{\infty}\left[\cos \left(n q_{1}\right)+\cos \left(n q_{2}\right)\right] \sin (n w t)
$$

Equation (2) is the main equation of the proposed inverter; $b_{n}$ is the amplitude of the harmonics order; $q_{1}$ , and $q_{2}$ are the switching angles to be optimized, and they must satisfy the following condition: $0<q_{1}<q_{2}$ $<90^{\circ}$. Ideally, for $V_{1}$ fundamental voltage desired, determination of switching angles $q_{1}$, and $q_{2}$ are possible so that $V_{\text {utb }}(w t)=V_{1} \sin (w t)$ and specific higher harmonics equal zero.

To control the peak value of the output voltage to be $V_{1}$ and eliminate the $3^{\text {rd }}$ order harmonics, the resulting harmonic equations shall be: 


$$
\begin{aligned}
& b_{1}=\frac{4 V_{d c}}{3 p}\left[\cos \left(q_{1}\right)+\cos \left(q_{2}\right)\right]=V_{1} \\
& h_{3}=\frac{4 V_{d c}}{9 p}\left[\cos \left(3 q_{1}\right)+\cos \left(3 q_{2}\right)\right]=0
\end{aligned}
$$

The fundamental voltage and the maximum obtainable voltage relate via the modulation index. Modulation index $m_{\mathrm{a}}$, is defined as the ratio of the fundamental output voltage $V_{1}$ to the maximum obtainable fundamental voltage $V_{\text {Imax }}$. The maximum fundamental voltage is obtained when all the switching angles are zero, i.e., $V_{1 \max }=4 V_{d c} / 3 \pi$. The expression for $m_{\mathrm{a}}$ is therefore $[7,10,17]$ :

$$
m_{a}=\frac{p V_{1}}{4 s V_{d c}}
$$

where $s$ is the number of switching angles, which also equals the number of DC sources. Equation (3) can be written as:

$$
\begin{aligned}
{\left[\cos \left(q_{1}\right)+\cos \left(q_{2}\right)\right] } & =2 m_{a} \\
{\left[\cos \left(3 q_{1}\right)+\cos \left(3 q_{2}\right)\right] } & =0
\end{aligned}
$$

Generally, equation $(9)$ can be written as

where $\quad F(q)=\left[\begin{array}{cc}\cos \left(q_{1}\right) & \cos \left(q_{2}\right) \\ \cos \left(3 q_{1}\right) & \cos \left(3 q_{2}\right)\end{array}\right] ;$ and $\quad B\left(m_{a}\right)=\left[\begin{array}{lll}2 m_{a} & 0 & 0\end{array}\right]^{T}$

Equation (6) represents a system of two transcendental equations known as SHE-OHESW equations, in terms of two unknowns: $q_{1}$, and $q_{2}$. For given values of $m_{a}$ (from 0 to 1 ), complete and all possible solutions for (5) are required when they exist with minimum computational burden and complexity. One solution approach for sets of nonlinear transcendental equations (6) is by applying an iterative method such as the Newton-Raphson method [18, 19].

To select the set generating the lowest harmonic distortion, the solution sets are examined for their corresponding total harmonic distortion. The computed THD in \% is defined by:

$$
\text { THD }(\%)=\frac{\sqrt{\sum_{n=2}^{\infty} V_{n}^{2}}}{V_{1}} \times 100 \%
$$

\section{The Newton-Rapson Method}

The Newton-Raphson (N-R) method is one of the most widely used methods for root-finding. It can be easily generalized to the problem of finding solutions of a system of non-linear equations. This method has been applied in numeric analysis. It requires only one initial value.

The N-R method is to be implemented to compute the switching angles for the system given by equation (9). Switching angles in the range 0 to $\pi / 2$ producing the desired fundamental voltage with the $3^{\text {rd }}$ or the $5^{\text {th }}$ harmonic components eliminated for a given modulation index are feasible solutions of equation (5).

In [20], the authors developed the N-R algorithm for cascade multilevel inverter; application to the proposed inverter is as follows:

1. Assume any random initial guess for the switching angles (say $q_{0}$ ) such as $0^{\circ}<q_{1}<q_{2}<90^{\circ}$

2. Set $m_{a}=0$.

3. Calculate $F\left(q_{0}\right)$ and $B\left(m_{i}\right)$ Jacobian $J\left(q_{0}\right)$

4. Compute correction $\Delta q_{0}$ during the iteration using relation, $\Delta q=J^{-1}\left(q_{0}\right)\left[B\left(m_{a}\right)-F\left(q_{0}\right)\right]$

5. Update the switching angles i.e. $q(k+1)=q(k)+\Delta q(k)$

6. Perform $q(k+1)=\cos ^{-1}[a b s(\cos (q(k+1)))]$ transformation to bring switching angles to feasible range.

7. Repeat steps (3) to (6) for sufficient number of iterations to attain error goal.

8. Increment $m_{\alpha}$ by a fixed step.

9. Repeat steps (2) to (8) for whole range of $m_{a}$.

10. Plot the switching angles as a function of $m_{\alpha}$. Different solution sets would be obtained.

11. Take one solution set at a time and compute complete solution set for the range of $m_{a}$ where it exits, 
Proceedings of International Conference on Engineering and Science for Research and Development (ICESReD) 2016, October 25-26, 2016, Banda Aceh, Indonesia

By following the above steps, all possible solution sets, when they exist, can be computed without any complex computation.

\section{Results and Discussion}

For the proposed single-phase five-level inverter, solution of two SHE-OHESW equations to get the few number of switching angles is required.

As discussed, one switching angle is used to produce the fundamental voltage while the remaining one eliminates the $3^{\text {rd }}$ order harmonic components. Solutions computed with an arbitrary initial guess as $m_{a}$ is incremented from 0 to 1 in steps of 0.01 .

Figures 4 and 5 show that the lowest harmonic content of the proposed five-level inverter's output voltage is $16.86 \%$ where the modulation index is 0.835 and the switching angles are respectively $17,06^{\circ}$, and $43.53^{\circ}$ for $q_{1}$, and $q_{2}$. Note that not all $m_{\mathrm{a}}$ in the range have a solution, e.g., there are solutions in intervals: $m_{\mathrm{a}} \in[0.45$, $0.869]$ only. Similarly for $m_{\mathrm{a}} \in[0,0.449]$, and $[0.869,1]$, owing to iteration divergence, there are no solvable solutions.

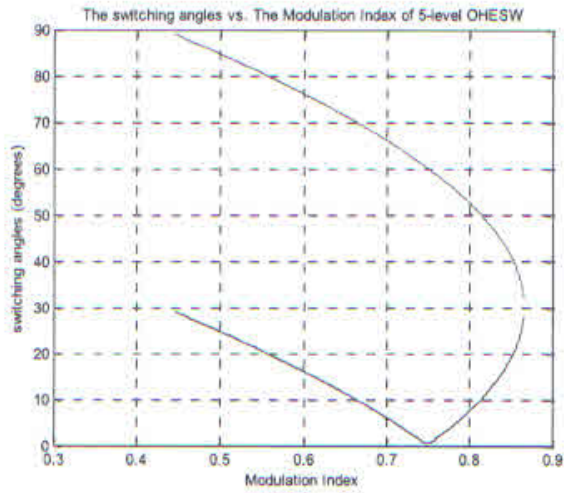

Figure 4: Solution set computed with an arbitrary initial guess

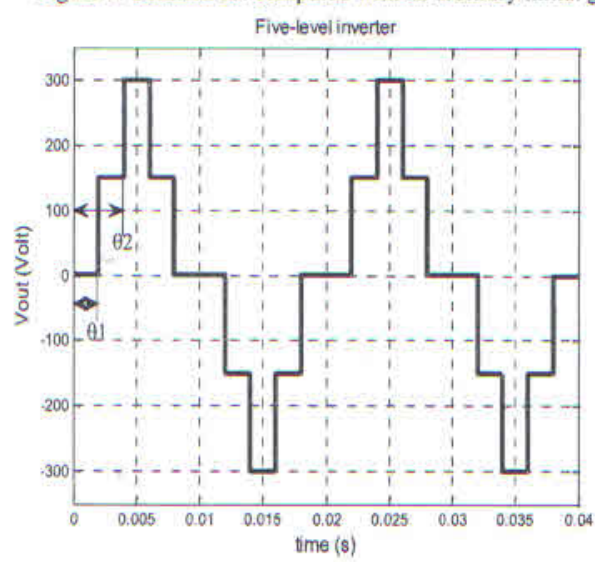

Figure 8: Output voltage for $q_{1}=36^{\circ}$, and $q_{2}=72^{\circ}$

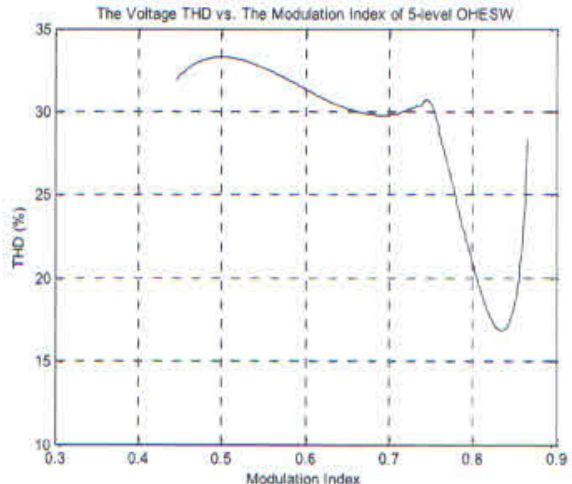

Figure 5: Voltage THD versus modulation index

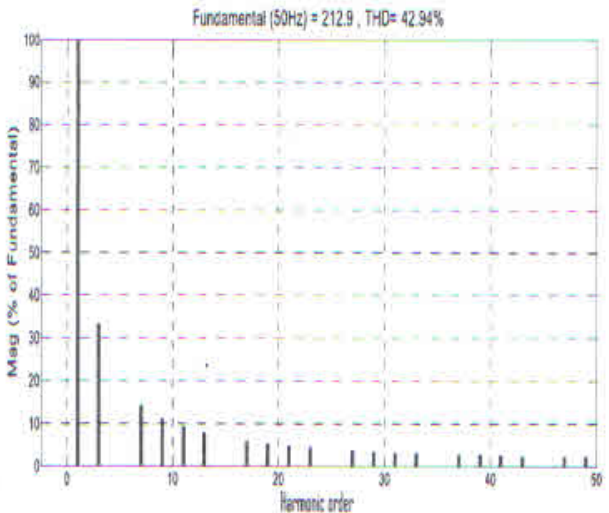

Figure 9: Harmonic content voltage for $q_{1}=36^{\circ}$, and $q_{2}=72^{\circ}$ 


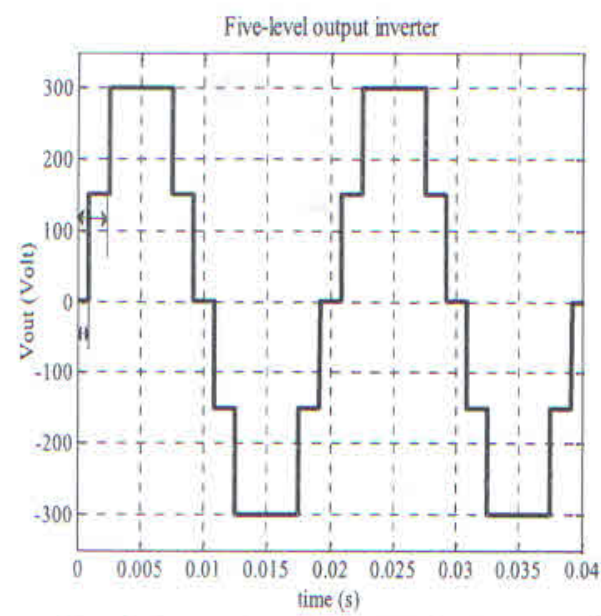

Figure 8; Output voltage for $q_{1}=17.06^{\circ}$, and $q_{2}=43.53^{\circ}$

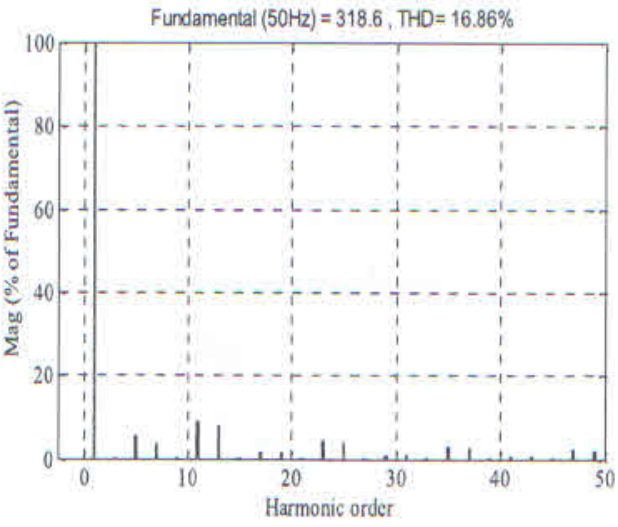

Figure 9: Harmonic content for $q_{1}=17.06^{\circ}$, and $q_{2}=43.53^{\circ}$

\section{Conclusions}

This paper presents the operational principles and the switching function of a single-phase five-level inverter. The inverter generates five levels of output voltages. A low frequency switching control algorithm for it has been developed. OHESW technique with Newton-Raphson method was employed to solve the nonlinear equations from the switching angles. The computed results were verified by simulation.

\section{References}

[1] A. Nabae, et al., "A New Neutral-Point-Clamped PWM Inverter," Industry Applications, IEEE Transactions on, vol. IA-17, pp. 518-523, 1981 .

[2] L. Jih-Sheng and P. Fang Zheng, "Multilevel converters-a new breed of power converters," Industry Applications, IEEE Transactions on, vol. 32, pp. 509-517, 1996.

[3] M. M. Renge and H. M. Suryawanshi, "Five-Level Diode Clamped Inverter to EliminateCommon Mode Voltage and Reduce $<$ formula $><$ img src="/images/tex/901.gif" alt="dv/dt" $></$ formula $>$ inMedium Voltage Rating Induction Motor Drives," Power Electronics, IEEE Transactions on, vol. 23, pp. 1598-1607, 2008.

[4] J. Rodriguez, et al., "Multilevel inverters: a survey of topologies, controls, and applications," Industrial Electronics, IEEE Transactions on, vol. 49, pp. 724-738, 2002.

[5] M. F. Escalante, et al., "Flying capacitor multilevel inverters and DTC motor drive applications," Industrial Electronics, IEEE Transactions on, vol. 49, pp. 809-815, 2002.

[6] O. Alonso, et al., "Cascaded H-bridge multilevel converter for grid connected photovoltaic generators with independent maximum power point tracking of each solar array," in Power Electronics Specialist Conference, 2003. PESC '03. 2003 IEEE 34th Annual, 2003, pp. 731-735 vol.2.

[7] K. El-Naggar and T. H. Abdelhamid, "Selective harmonic elimination of new family of multilevel inverters using genetic algorithms," Energy Conversion and Management, vol, 49, pp. 89-95, 2008.

[8] B. Ozpineci, et al., "Harmonic optimization of multilevel converters using genetic algorithms," Power Electronics Letters, IEEE, vol. 3, pp. 92-95, 2005.

[9] P. M. Pandi and N. Devarajan, "Optimization of power quality in cascaded multilevel inverter-genetic algorithm approach," in Computing Communication and Networking Technologies (ICCCNT), 2010 International Conference on, 2010, pp. 1-7.

[10] J. N. Chiasson, et al., "Elimination of harmonics in a multilevel converter using the theory of symmetric polynomials and resultants," Control Systems Technology, IEEE Transactions on, vol. 13, pp. 216-223, 2005.

[11] F. Filho, et al., "Real time selective harmonic minimization for multilevel inverters connected to solar panels using Artificial Neural Network angle generation," in Energy Conversion Congress and Exposition (ECCE), 2010 IEEE, 2010, pp. 594-598. 
Proceedings of International Conference on Engineering and Science for Research and Development (ICESReD) 2016, October 25-26, 2016, Banda Aceh, Indonesia

[12] I. Khoukha, et al., "ANN control of nine level NPC voltage inverter based on selective harmonics elimination," in Electrical Machines and Power Electronics, 2007. ACEMP '07. International Aegean Conference on, 2007, pp, 587-591.

[13] M. Honkala, et al., "Improving the convergence of combined Newton-Raphson and Gauss-Newton multilevel iteration method," in Circuits and Systems, 2002. ISCAS 2002. IEEE International Symposium on, 2002, pp. II-229-II-232 vol.2.

[14] Q. Li, et al., "Investigation of the Harmonic Optimization Approaches in the New Modular Multilevel Converters," in Power and Energy Engineering Conference (APPEEC), 2010 Asia-Pacific, 2010, pp. $1-6$.

[15] T. Sarikurt, et al., "Simplified multilevel inverter model and its control with selective harmonic elimination method," in Electrical, Electronics and Computer Engineering (ELECO), 2010 National Conference on, 2010, pp. 283-287.

[16] K. Chaniago, et al., "Novel fundamental-frequency-modulated modified H-bridge single-phase sevenlevel inverter for stand-alone photovoltaic system," in Clean Energy and Technology (CET), 2011 IEEE First Conference on, 2011, pp. 225-230.

[17] A. Muthuramalingam, et al., "Selective harmonic elimination modulation method for multilevel inverters," in Power Electronics, 2006. IICPE 2006. India International Conference on, 2006, pp. 4045 .

[18] H. S. Patel and R. G. Hoft, "Generalized Techniques of Harmonic Elimination and Voltage Control in Thyristor Inverters: Part I--Harmonic Elimination," Industry Applications, IEEE Transactions on, vol. IA-9, pp. 310-317, 1973

[19] L. M. Tolbert and T. G. Habetler, "Novel multilevel inverter carrier-based PWM method," Industry Applications, IEEE Transactions on, vol. 35, pp. 1098-1107, 1999.

[20] B, D. Jagdish Kumar, and Pramod Agarwal, "Selective harmonic elimination Technique for a multilevel inverter," Fifteenth national Power SYstem Conference (NPSC) IIT Bombay, p. , 2008. 